\title{
ESSE AIRES, ESSE MACHADO: UM ESTUDO SOBRE O MEMORIAL DE AIRES.
}

José Marcos Resende 01iveira*

RESUMO:

\author{
As complexas relações entre a vida e a obra de Machado de \\ Assis em seu último romance, Memorial de Aires, evidenciam \\ um traço autobiográfico nas iniciais do nome próprio impressas \\ na capa do livro. Trata-se de um estudo sobre memória, \\ escrita e autoria no Memorial de Aires. \\ PALAVRAS-CHAVE: Machado de Assis, Memorial de Aires, memória, \\ autoria.
}

A vida e a obra de um escritor são interdependentes. E pensar uma obra no tempo em que foi escrita, assim como pensar na mão do autor como extensão de um corpo que escreve o texto, ali no momento em que produz, no momento em que cria, pode lançar luz sobre essa complexa relação entre vida e obra. Isto se aplica muito apropriadamente a Machado de Assis. A vida de Machado revela a trajetória de um sujeito que percorre, sustenta e constrói o seu desejo - o desejo de se tornar um grande escritor da literatura brasileira. Para isto, enfrentará os obstáculos e as dificuldades que toda travessia oferece, até que, no decorrer dessa travessia, forjará um nome, ou se tornará um escritor de renome.

Memorial de Aires foi o último romance escrito por esse genial criador de histórias. Desde a sua publicação, ou nos meses que a antecederam, segundo as cartas trocadas entre Machado de Assis e Mário de Alencar, percebeu-se um traço autobiográfico no livro. A partir daí, escrever sobre o romance implicava também escrever sobre o autor, sobre a vida do escritor, evidenciando aqui e acolá traços dele em personagens como Aguiar e Aires, bem como traços de Carolina, sua mulher, na personagem Carmo.

* Mestre em Letras: Estudos Literários (Área de concentração: Literatura Brasileira), 2001. 


\section{EMTESE}

Belo Horizonte, v. 6, p. I-253, ago. 2003

No momento em que escreveu o livro, havia dois anos que Machado de Assis perdera Carolina, companheira e leitora atenciosa dos seus textos. Não somente Mário de Alencar, em carta enviada a Machado de Assis em 16 de dezembro de 1907 (Machado de Assis, 1957: 244-248), mas, também, posteriormente, Lúcia Miguel Pereira e Barreto Filho encontraram evidentes pontos de contato entre a vida e a obra do escritor. Lúcia Miguel Pereira, em seu livro Machado de Assis: estudo crítico e biográfico, sublinha, por exemplo, que Carolina, após o falecimento, viria de tal modo fixar-se no Memorial de Aires que o livro poderia ser considerado um "poema de amor conjugal". Isto é: Machado de Assis teria se inspirado em sua própria vida em comum com Carolina para descrever os anos iniciais do casal Aguiar (Pereira, 1988).

Aproximar a vida e a obra do escritor no Memorial de Aires nos exige cuidado e sensibilidade. E embora muitos outros estudiosos tenham se aventurado nessa tarefa complexa e movediça, caberia ainda refletir sobre o vocábulo Carolina e seus efeitos neste último romance. Isto sem nos esquecermos de um outro ponto de contato, também colocado em foco pelas cartas acima citadas, que é a marca que a arte imprime sobre o autor. Ou, como bem está dito nas palavras de Barreto Filho, em Introdução a Machado de Assis, a arte servia para Machado como um consolo metafísico, seria para ele uma forma de "neutralizar a perda com o processo de criação" (Barreto Filho, 1947: 215). Deste modo, segundo o autor, do processo da perda da companheira surge a possibilidade da escrita.

Duas palavras, "Carolina" e "arte", permeiam a construção do diário. Contudo, o traço autobiográfico surgirá como óbvio, na capa do romance, nas letras iniciais do título M. de A. Essas letras são as iniciais do autor-editor que escreve a introdução do livro em forma de "Advertência" ao leitor, são também as letras iniciais do nome próprio Machado de Assis e do romance Memorial de Aires (Silviano Brandão, 2000: 193) e ainda as iniciais de outros dois nomes do círculo de afeto do escritor, Mário de Alencar e Magalhães de Azeredo. Em outras palavras, são letras que costuram, urdem, em um mesmo ponto, vários significantes, várias palavras representantes de afeto tanto para o escritor quanto para a personagem Aires, pois o memorial é dele.

Anotando em seu diário os "pensamentos de vida formulados", os "pensamentos idos e vividos" (Machado de Assis, 1997: 658) utilizando-se de palavras simples, 
concisas e exatas, Aires constrói o seu memorial. No romance em forma de diário Aires escreve impressões, anotações e reflexões sobre o cotidiano. 0 autor-editor M. de A afirma ter feito os recortes antes da edição, alertando-nos que a obra foi "desbastada e estreita, conservando só o que liga o mesmo assunto" (Machado de Assis, 1992: 1096). E o que "liga o mesmo assunto" é, de um lado, a história da viúva Noronha, Fidélia; de outro, uma pergunta que surge como aposta entre Aires e sua irmã Rita logo no início do romance, em decorrência do estado civil e do nome da personagem Fidélia, sobre a fidelidade dela ao ex-marido: Fidélia se casa ou não se casa novamente?

Embora sem um grande enredo, aqui entendido como sem os revestimentos imaginários de uma grande história, o diário de Aires é uma reflexão sobre o ato de escrever, pois esse verbo aparece como central nas ocupações do diplomata aposentado. No diário, a escrita dobra sobre si mesma, descreve-se a si mesma. Antes, Aires escrevia nos "lazeres do ofício" da diplomacia; depois de aposentar-se, a escrita passa a ser o seu ofício.

Contudo, "os trinta e tantos anos de diplomacia" (Machado de Assis, 1992: 1097) acabaram por deixar vestígios na escrita do diário. Em Esaú e Jacó, Aires dizia que "toda a diplomacia está em dois verbos parentes: descobrir e encobrir" (Machado de Assis, 1992: 1070). Do tempo de diplomata para o tempo de vadiação, tempo propício para o ato de escrever, Aires retém dois aspectos. Primeiro, ele compõe os seus relatos de tal maneira que o leitor, em um primeiro instante, não percebe as controvérsias dos temas, as dualidades dos assuntos, o espaço que se abre entre a intenção e o gesto, passando-1he uma idéia de se tratar de um romance simples. Segundo, ao resumir a diplomacia através daqueles dois verbos, Aires os encena na tessitura do diário. Primeiro, desvela a cena, depois a encobre parcialmente, ao analisá-la sob vários ângulos. Seria algo como o movimento que faz um compasso ao se abrir em dois pontos extremos, para, em um terceiro momento, criar o distanciamento de que o ato da escrita necessita.

Nos movimentos pulsionais de descobrir e encobrir e na forma simplesmente simples do Memorial, o narrador mostra feridas abertas nas frustrações, privações e desvios de afetos, fazendo do diário uma espécie de psicopatologia da vida cotidiana, como se o ato de viver fosse sempre um arranjo imperfeito e precário 


\section{EMTESE}

Belo Horizonte, v. 6, p. I-253, ago. 2003

entre o indivíduo e a sociedade em que vive. Acontece que a maestria do escritor é tamanha que exige de nós esforço para percebermos o desarranjo que se encobre nesse ritmo aparentemente suave e estável das coisas.

Ódios recalcados, amores mal resolvidos, intrigas, ambigüidades em relação aos sentimentos, roubos, difamações, ressentimentos, desilusão, inibições, retraimentos, enganos, decepções e desamparo - eis alguns temas abordados pela pena do diplomata que escolhe bem as palavras, ajeitando-as para que elas não assustem o leitor, "pingando as palavras graves e obscuras" em um trabalho manual e árduo de catar os vocábulos adequados para expressar as opiniões e os fatos.

Os resíduos de maledicência, agressividade, ódio e mal que permanecem nos relatos de Aires, personificados nos comentários de D. Cesária, mas não indiferentes aos sentimentos às vezes compartilhados pelo narrador, são os que dão "interesse a um tédio e movimento a um defunto" (Machado de Assis, 1992: 1140). Machado de Assis, avant la lettre, representa o dualismo pulsional da última teoria das pulsões, tal como foi estabelecido por Sigmund Freud: pulsões de vida e pulsões de morte na escrita de Aires, pois o diário se faz no litoral e no confronto entre a vida e a morte, as duas forças presentes no texto.

Junto com as anotações e reflexões sobre o cotidiano, o livro também aborda as memórias do narrador. Nesse caso, a própria escrita engendra a memória, a qual se mostra lacunar e incompleta. Além disso, as vozes, que englobam rumores, sons, ecos, alaridos, sussurros, ruídos, canções, citações de outros autores e silêncios, também interferem na escrita, deslocando-a e, consequentemente, também deslocando a memória para outros fatos e acontecimentos.

As vozes estão presentes no relato do Conselheiro através da musicalidade. São cantigas de despedida, pregões de vendedores, barulhos da rua, burburinhos da vida cotidiana, ecos de lugares, fatos que participam da construção da memória do narrador, provocando deslizamentos metafóricos e metonímicos em seu texto e produzindo novos significantes e significados.

E se os ritmos musicais do diário ecoam o vazio, a vacuidade e a vaidade das lidas humanas, eles também enfatizam o poder da criação que, enfim, é a criação da própria obra de arte - o diário de Aires -, palavra que condensa três outros significados: ar, coisa vã e ária. 


\section{ABSTRACT :}

This article analyses the relations between Machado de Assis' life and work in his last novel, Memorial de Aires. Unveiling and veiling - two verbs, which are not only related but also a synthesis of Aires's diplomatic job, leave traces on Conselheiro' writing. Aires creates scenes and narratives from the gaps of the text, bringing about landslides of metaphors, thus producing new significant and meanings.

KEY WORDS: Machado de Assis, Memorial de Aires, memory, authorship.

\section{REFERÊNCIAS BIBLIOGRÁFICAS}

ALENCAR, Mário de. Alguns escritos. Rio de Janeiro: Garnier, 1910.

BARRETO FILHO. Introdução a Machado de Assis - em apêndice: "Garção e Assis de Nestor Vitor". Rio de Janeiro: Livraria Agir Editora, 1947.

BOSI, Alfredo. O enigma do olhar. São Paulo: Editora Ática, 1999.

CÂNDID0, Antônio. Esquema de Machado de Assis. In: Vários escritos. São Paulo: Duas Cidades, 1995.

MACHADO DE ASSIS, Joaquim Maria. Correspondência. Obras completas de Machado de Assis, v. 31; Rio de Janeiro, São Paulo, Porto Alegre: W.M. Jackson Inc., 1957.

- Obra completa. Rio de Janeiro: Aguilar, 1992. v. 1. p. 945-1093: Esaú e Jacó; p. 1095-1200: Memorial de Aires.

- Obra completa. Rio de Janeiro: Aguilar, 1997. v. 2. p. 657-733: Reliquias de Casa Velha.

PEREIRA, Lúcia Miguel. Machado de Assis: estudo crítico e biográfico. Belo Horizonte: Itatiaia; São Paulo: Editora da Universidade de São Paulo, 1988.

SILVIANO BRANDÃO, Ruth. A travessia da escrita machadiana. In: Scripta Literatura, PUC Minas (Belo Horizonte), v. 3, n. 6, p. 187-193, $1^{\circ}$ sem. 2000. 